\title{
EL APORTE DE LAS FUERZAS MILITARES A LA PAZ EN Colombia
}

\author{
Mayor General (RA) JUAN GUILLERMo GARCÍA SERNA ${ }^{l}$
}

Un alza en el pasaje de buses en Bogotá llevó a un grupo de universitarios y otros inconformes a realizar mítines en el cruce de la Avenida Jiménez por carrera Séptima. En tanto repitieron los mítines durante un par de meses y cada vez más violentos, al grupo de inconformes se fueron uniendo toda suerte de opositores políticos al Frente Nacional hasta ex guerrilleros amnistiados. Reunidos luego en asamblea el grupo adoptó el nombre $\mathrm{MOEC}^{2}$ y al cabo de dos años, en 1961, ya articulaba cuadrillas en Cauca, Urabá y Vichada para tomarse el poder por las armas (FrANCO, 2012). En el caso del Vichada el gobierno del presidente Lleras Camargo ordenó al Comando General de las Fuerzas Militares actuar de inmediato.

En consecuencia, el Ejército Nacional primero envió una comisión que, luego de estudiar la situación, recomendó promover la acción comunal y la atención social a los indígenas. En seguida envió el Batallón Colombia cuyo jefe, el coronel Valencia Tovar, determinó dos cursos de acción: recuperar el control territorial y mejorar la vida de los colonos. Pero, en octubre de 1961, la cuadrilla del Vichada atacó a Puerto López en lo que sería la primera acción de este tipo emulando el modelo cubano (DíAz, 2013, p. 93).

Lo anterior confirma que en 1961, cuando estalló el conflicto armado interno en Colombia, fue de la mano de grupos armados ilegales cuya pretensión era tomarse el poder. Esta caracterización del conflicto, avalada por miembros de la Comisión Histórica (2015) de La Habana como Gutiérrez, Duncan, Giraldo y Torrijos, no discute si las causas del conflicto se remiten a un alza en el pasaje de buses o deben buscarse en el origen de los tiempos como sugirieron otros comisionados. Esta caracterización evidencia que las vías de hecho asumidas

Candidato a PhD en Derecho, Magíster en Seguridad y Defensa Nacional, Especialista en Derechos Humanos y Derecho Internacional Humanitario. Especialista en derecho penal. Abogado. Mayor General (RA) de la Fuerza Aérea Colombiana.

2 MOEC: Movimiento Obrero Estudiantil Campesino, primero se llamó "Movimiento Obrero Estudiantil 7 de enero", fundado en esa fecha de 1959 por Antonio Larrota acogió bandoleros como 'Pedro Brincos' y 'Minuto' Colmenares. En 1965 una escisión dio origen al MOIR, liderado por Francisco Mosquera (Franco, 2012). 
por algunos ciudadanos, independiente de sus motivaciones, no han contribuido a la paz en Colombia.

Como también evidencia que las Fuerzas Militares, aún actuando por órdenes expresas del Ejecutivo, han cumplido también con su deber constitucional de contribuir al desarrollo del país. En el caso del Vichada en 1961 las Fuerzas Militares ya procuraban paliar la situación de poblaciones cuyo aislamiento era aprovechado por los grupos ilegales para sus exacciones, contra la misma población y contra el Estado colombiano.

\section{EL ESTADO-NACIÓN Y LA PAZ}

Las particularidades del conflicto colombiano no le sustraen de la caracterización de la guerra. KEEGAN, el destacado historiador inglés, sostuvo que la guerra está arraigada en el corazón humano, en el que se diluyen los propósitos racionales (KEEGAN, 1995, p. 21). Ello para afirmar luego que el gran avance de la cultura occidental no fue desaprobar la guerra sino legitimar su empleo, es decir, establecer pactos. Uno de esos pactos fue crear ejércitos oficiales, regidos por sus propias reglas las que se conocen hace siglos como fuero militar. Otro pacto fue limitar el uso de la violencia, cuya expresión es el derecho internacional humanitario. De allí que el objetivo de la guerra no es aniquilar al contrincante, pues desde Sun Tzu se ha dicho que el mejor estratega es el que logra la victoria sin siquiera combatir.

Es deber de los colombianos para consolidar la paz, reconocer que como nación hemos sido consecuentes en ese propósito. A través del Estado, se han procurado todos los instrumentos a tal fin. Incluso en exceso, entre 1981 y 2006 , se cuenta casi una veintena de comisiones y consejerías para negociar con los grupos armados ilegales (FIP, 2003). La lista de amnistías e indultos otorgados por los diferentes gobiernos colombianos incluye más de cincuenta, si se prolonga al siglo XIX (SÁNCHEZ, 1985, p. 217).

Recuérdese que cuando en 1961 estalló el conflicto, el país se esforzaba por superar otro conflicto donde el bipartidismo tradicional fue actor principal. Pero si se observan ambos momentos a la luz de los instrumentos usados por el Estado, debe admitirse que la nación ha sido más que generosa para preservar la paz. Justo en 1957 el país votó un plebiscito para instaurar el régimen del Frente Nacional, un medio por el cual los dos partidos tradicionales coadyuvaban a mantener la paz. En 1991, como resultado de diálogos de paz y la desmovilización de algunos grupos armados, el país aceptó reformar su Constitución Política para dar cabida a las minorías étnicas y políticas, fortalecer la democracia representativa y el respeto a los derechos humanos, entre otros logros garantistas para la pacífica convivencia de los colombianos. 
Algunos refieren que entre 1982 y 1987 fue la primera vez que hubo propiamente negociaciones con algunos grupos armados ilegales (VILLARRAGA, 2009 , p. 2). En ese marco se estableció una tregua bilateral con tres grupos, se decretó una amnistía y garantías para sus delegados en las mesas de diálogo. Aunque el contexto sociopolítico de entonces llevó a la ruptura del proceso con algunos, se firmó la paz con el M-19, el EPL, el PRT y el MAQL; sin olvidar que ese mismo contexto llevó a la reforma constitucional de 1991 ya mencionada. Más reciente, entre 1998 y 2002, el país fue más que generoso al conceder una zona de distensión para los diálogos con el grupo FARC, convocando a la comunidad internacional y al persistir durante tres años en el proceso mientras aquel grupo intensificaba sus exacciones.

El Estado también incentivó la desmovilización de los miembros de los grupos armados. Tanto en 1982 como en 1990 tal desmovilización hizo parte de los procesos de paz ya aludidos. La exigencia de un grupo ilegal de izquierda para dialogar era que el Estado promoviera la desmovilización de los grupos ilegales de autodefensa. Lo que se cumplió entre 2003 y 2006, pese al controvertido proceso con estos y los alcances de la Ley 975 que tocan a la justicia transicional. No obstante, apenas en 2012, después que una política integral del Estado debilitó su influencia sobre la población y neutralizó la cúpula dirigente, aquel grupo de izquierda aceptó reiniciar diálogos.

En función de resolver las causas del conflicto en Colombia, solo recientemente los planes de desarrollo nacional hicieron confluir ambas instancias (causas vs. desarrollo). Ello fue más notorio desde el "Plan Nacional de Rehabilitación" del gobierno Betancur (1982-1986), cuando también se estableció la elección popular de alcaldes, un paso en la descentralización y fortalecimiento de la democracia. Su sucesor, el gobierno Barco (1986-1990), estableció una segunda comisión de estudio con recomendaciones respecto al conflicto que dirigió el sociólogo Gonzalo Sánchez y publicadas como "Comisión de Estudios sobre la Violencia" (1988).

\section{LAS FF.MM. Y LA PAZ}

Debe recordarse que en 1953 las Fuerzas Militares tuvieron que asumir el gobierno para lograr la paz entre los grupos armados ilegales de todos los partidos, en conflicto durante el lustro previo. Entonces se promovió la desmovilización y el desarme voluntario de tales grupos. Fue el mismo gobierno de las Fuerzas Militares el que decretó la primera amnistía entonces para los individuos comprometidos en el conflicto. Así como creó la "Oficina de Rehabilitación y Socorro" para cumplir las tareas de desarrollo local y atención a las víctimas.

Los grupos comunistas se negaron a entregar las armas, al tiempo que algunos desmovilizados prefirieron organizar bandas dedicadas al pillaje en los campos. Por esta razón, en 1958, junto con la firma del acuerdo del "Frente Nacional" 
para desactivar la confrontación del bipartidismo tradicional, se decretó una segunda amnistía, se reorganizó el "Programa de Rehabilitación" y se encargó a una comisión de estudiar las causas del conflicto. El estudio publicado bajo el título "La violencia en Colombia" y dirigido por Monseñor Germán Guzmán, equivale a lo que hoy "podemos considerar el informe de una comisión de la verdad” (VILlarRaGa, 2009, p. 9).

Lo cierto es que la acción integral para superar las causas del conflicto fue también iniciativa de las Fuerzas Militares. El ya citado coronel Valencia Tovar la puso en práctica en 1959, en el occidente de Caldas, para contrarrestar la acción de los bandoleros allí (VALENCIA, 1992, p. 370); de nuevo en 1961 en el Vichada, como ya se mencionó. Precisamente, en 1960, al ser nombrado Comandante del Ejército, el general Alberto Ruiz Novoa anunció que la Fuerza Armada contribuiría a desarrollar la infraestructura y recuperar el tejido social en las regiones donde el conflicto era latente. Directriz que amplió al desempeñarse como Ministro de Defensa, entre 1962 y 1965, coordinada con la política gubernamental de reforma agraria, construcción de carreteras, escuelas, puestos de salud, acueductos y sistemas de irrigación, con el apoyo estadounidense de la Alianza para el Progreso (RemPe, 1995).

Desde entonces las Fuerzas Militares están comprometidas con la paz. Otrora adelantaron la construcción de obras que conforman la infraestructura del país, entre ellas la carretera al Mar en Urabá, la Marginal de la Selva, la transversal de La Macarena, los aeropuertos de Palanquero y de Acandí. Además de ser las primeras en acudir cuando las crisis por la erupción del volcán Nevado del Ruiz en 1985, el desbordamiento del río Páez en 1994, los sismos de Pereira en 1995 y Armenia en 1999 (PAREDES, 2010); hoy conforman unidades de prevención y atención de desastres. También participan en el programa nacional de desminado, desactivando los artefactos explosivos improvisados (AEI) que sembraron en los campos los grupos ilegales.

\section{REFERENCIAS}

Comisión Histórica del Conflicto y sus Víctimas (2015, febrero). Contribución al entendimiento del conflicto armado en Colombia. Recuperado de:https:// www.mesadeconversaciones.com.co/sites/default/files/informe $\% 20$ comisi_n $\% 20$ hist rica $\% 20$ del $\% 20$ conflicto $\% 20 \mathrm{y} \% 20$ sus $\% 20$ v_ctimas. $\% 20$ la $\% 20$ habana $\% 2 \mathrm{c} \% 20$ febrero $\% 20 \mathrm{de} \% 202015$.pdf

DíAz, J. (2013). La crítica de las armas: Tulio Bayer Jaramillo y el levantamiento armado del Vichada, 1961-1962. Historia y Espacio, 41: 81-103. Recuperado de: $\mathrm{http}: /$ historiayespacio.univalle.edu.co/index.php/historiayespacio/ article/view/2533 
FrANCO, R. (2012). El MOEC 7 de enero, origen de la guerrilla revolucionaria en Colombia. Bogotá: Universidad Javeriana (Trabajo de pregrado en Historia). Recuperado de: http://repository.javeriana.edu.co/handle/10554/14295

Fundación Ideas para la paz-FIP (2003). Comisiones y Consejerías del Gobierno Nacional encargadas de los procesos de acercamiento y negociación con los grupos ilegales armados. Boletín informativo, 7. Recuperado de: http://www. ideaspaz.org/proyecto03/boletines/download/boletin07

Keegan, J. (1995). Historia de la guerra. Barcelona: Planeta.

Paredes, L. (2010). Ingenieros militares en Colombia 200 años de historia: 1810-2010. Bogotá: Planeta.

Rempe, D. (1995, Winter). Guerrillas, Bandits, and Independent Republics: US Counter-insurgency Efforts in Colombia 1959-1965. Small Wars and Insurgencies, 6 (3).

SÁNCHEZ, G. (1985). Las raíces históricas de la amnistía o las etapas de la guerra en Colombia. En: Ensayos de historia política social y política del siglo XX. Bogotá: El Áncora.

Valencia, Á. (1992). Testimonio de una época. Bogotá: Planeta.

Villarraga, A. (2009). Procesos de paz entre el estado y las guerrillas en Colombia, experiencias y lecciones. 